\title{
Clinical and genetic factors associated with kidney tubular dysfunction in a real-life single centre cohort of HIV-positive patients
}

\author{
S. E. Salvaggio ${ }^{1+}$, A. Giacomelli ${ }^{1 *+}$, F. S. Falvella ${ }^{2}$, M. L. Oreni ${ }^{1}$, P. Meraviglia ${ }^{3}$, C. Atzori ${ }^{3}$, E. G. I. Clementi ${ }^{4,5}$,
} M. Galli ${ }^{1}$ and S. Rusconi ${ }^{1^{*}}$ (D)

\begin{abstract}
Background: Tenofovir (TDF) is one of the most widely used antiretroviral drug. Despite the high degree of tolerability a small percentage of patients experienced alteration in tubular function during TDF use. Intracellular TDF disposition is regulated by ATP-binding cassette (ABC) drug efflux transporters and, a reduced transport activity may be implicated in accumulation of TDF into the cells. The aim of our study was to assess the major determinants of TDF associated tubular dysfunction (KTD) in a real-life setting including the usefulness of single-nucleotide polymorphisms (SNPs) mapping into ABCC2, ABCC4 and ABCC10 genes.
\end{abstract}

Methods: We retrospectively analyzed all HIV positive patients who were followed at the Infectious Diseases Unit, DIBIC Luigi Sacco, University of Milan from April 2013 to June 2016. All patients treated with TDF who underwent a genotypization for the functional variants mapping in ABCC2 rs717620 (-24 C > T), ABCC4 rs1751034 (3463 A > G) and ABCC10 rs2125739 ( $>$ > C) were evaluated. KTD was defined as the presence of urine phosphate wasting and/ or proteinuria at $24 \mathrm{~h}$ urine analysis.

Results: One hundred fifty-eight patients were genotyped, of which 42 (26.6\%) experienced signs of KTD. No statistical significant differences were observed among patients with or without KTD regarding age, gender, ethnicity and comorbidities (hypertension and diabetes). The percentage of patients with KTD was higher among those with "GG" genotype at rs 1751034 of ABCC4 compared to patients without KTD [6 (14.3\%) vs 4 (3.5\%), $p=0.01]$. No statistical significant differences were observed regarding the distribution of ABCC2 and ABCC10 SNPs. Carriers of " $G$ " allele in homozygous status at rs 1751034 of ABCC4 showed a significant association with KTD (Odds Ratio 4.67, 95\% Cl 1.25-17. $46, p=0.02)$ in bivariate analysis, but this association was lost in multivariable analysis. A significant association between bone diseases and KTD was observed (Odds Ratio 3.178, 95\%Cl 1.529-6.603, $p=0.002$ ).

Conclusions: According to our results ABCC4 rs 1751034 could be a genetic determinant of KTD; however validation studies are needed for therapy personalization. Noteworthy, a strong association between bone disease and KTD was also observed.

Keywords: Tenofovir DF, HIV-1, Pharmacogenetics, Tubular dysfunction

\footnotetext{
*Correspondence: andrea.giacomelli@unimi.it; stefano.rusconi@unimi.it

${ }^{\dagger}$ Equal contributors

${ }^{1}$ Infectious Diseases Unit, DIBIC Luigi Sacco - University of Milan, Milan, Italy

Full list of author information is available at the end of the article
} 


\section{Background}

Tenofovir disoproxil fumarate (TDF), a prodrug of Tenofovir, is a nucleotide reverse-transcriptase inhibitor used for the treatment of human immunodeficiency virus type 1 (HIV-1) infection. It is widely used because of its high potency, good safety profile, convenient once daily dosing and relatively minimal adverse reactions [1]. After absorption, TDF is converted to tenofovir that then is phosphorylated intracellularly to tenofovir diphosphate, an active analog, which inhibits HIV reverse transcriptase, arresting the elongation of DNA chain. Tenofovir is eliminated by renal excretion through glomerular filtration and active tubular secretion. Although tenofovir causes a mild degree of nephrotoxicity, several cases of Fanconi syndrome and acute renal failure have been reported in patients on this therapy $[2,3]$. The mechanism of tenofovir-induced kidney injury isn't completely understood. Mitochondrial damage in proximal renal tubular cells is observed in patients with significant tenofovir induced kidney tubular dysfunction (KTD) [4]. Furthermore, because characteristics and severity of KTD vary among individuals, the role of host genetics seems to be influential. Tenofovir is secreted into tubular lumen by energy-dependent pumps, Multidrug-Resistance Proteins 2 (MRP2), MRP4 and MRP7 encoded by genes ABCC2, $\mathrm{ABCC} 4$ and $\mathrm{ABCC} 10$, respectively $[5,6]$. Therefore, genetic variants affecting these transport activity may be implicated in tenofovir-accumulation into the cells and in tenofovir-KTD. Previous studies have shown that some Single-Nucleotide Polymorphism (SNPs) into ABCC2, $\mathrm{ABCC} 4$ and $\mathrm{ABCC} 10$ genes are associated with higher tenofovir plasma and/or intracellular levels [7-10]. More in details, for ABCC2 rs717620 at position $-24(-24 \mathrm{C}>\mathrm{T})$, individual with KDT was significantly higher in $\mathrm{CC}$ than $\mathrm{CT} / \mathrm{TT}$ carriers and, a correlation between ABCC2 CC $(-24 \mathrm{C}>\mathrm{T})$ and a higher plasma tenofovir concentration was also reported $[6,11]$. A study by Kiser et al. observed that patients carrying the $\mathrm{ABCC} 43463 \mathrm{~A} \rightarrow \mathrm{G}$ variation had lower renal clearance of tenofovir than those without. Finally, two SNPs mapping in ABCC10 gene (rs9349256 and rs2125739) and their haplotype were significantly associated with KTD [10].

The aim of this study was to investigate the major determinants of TDF associated tubular dysfunction (KTD) including the correlation between polymorphisms in ABCC2, $\mathrm{ABCC} 4$ and $\mathrm{ABCC} 10$ genes and the tenofovir-induced KTD in a mono-centric cohort of HIV-1 positive patients.

\section{Methods}

We performed a single centre retrospective observational cohort study in the cohort of patients followed at the University Infectious Disease Unit of Hospital Luigi Sacco in Milan from April 2013 to June 2016. All patients who had been treated with a TDF-containing antiretroviral regimen and were referred to our out-patient clinic for the management and prevention of antiretroviral toxicities underwent, as part of clinical practice assessment, a genotyping for $\mathrm{ABCC} 2$ rs717620 ( $-24 \mathrm{C}>\mathrm{T}), \mathrm{ABCC} 4$ rs1751034 (3463 A > G) and ABCC10 rs2125739 (T > C). Genomic DNA was isolated from peripheral blood cells using an automatic DNA extraction system (Maxwell ${ }^{\bullet} 16$ System, Promega) according to the manufacturer's instructions. All genotypes were determined by Real-Time PCR, using a panel of LightSNiP from TIB-MolBiol (assays based on SimpleProbe ${ }^{\circ}$ ). At the end of the amplification a melting curve analysis was performed (LightCycler 480, Roche). All data were collected in an electronic database. We collected data on gender, epidemiology, race, immuno-virological situation at the start of TDF, antiretroviral history, comorbidities (bone, cardiovascular, diabetes) and urine examination comprehensive of a $24 \mathrm{~h}$ sample. We defined KTD in our cohort as the presence of abnormal proteinuria (24 h urine proteins $>150 \mathrm{mg}$ ) and/or phosphaturia (24 h urine phosphate $>1200 \mathrm{mg}$ ) at $24 \mathrm{~h}$ urine collected during the period of treatment with TDF $[12,13]$. The definition of osteopenia and osteoporosis were based on DEXA scan assessment: bone mineral density Z-score between -1 and -2.5 standard deviation (SD) and below $-2.5 \mathrm{SD}$, respectively. Hypertension was defined as having a blood pressure $>140 / 90 \mathrm{mmHg}$ in two consecutive assessments or if the patient was on antihypertensive drugs. Diabetes was defined as having a fasting glucose level $>126 \mathrm{mg} / \mathrm{dL}$ in two consecutive determination or if the patient was taking antidiabetic drugs.

The aim of our study was to assess the distribution of the different $\mathrm{ABCC} 2, \mathrm{ABCC} 4$ and $\mathrm{ABCC} 10$ genotypes in patients treated with TDF with or without KTD. Baseline characteristics were compared between patients with or without KTD by using a descriptive statistical analysis ( $\mathrm{x} 2$ or Fisher's exact test for categorical variables and MannWhitney test for continuous variables). Associations between genotypes and KTD were tested by univariate and multivariate logistic regression analyses. The impact of all variables was estimated with univariate analysis, and those with $P$ value $<0.20$ were incorporated into multivariate analysis. Statistical significance was defined at 2-sided $P$ value $<0.05$. To perform statistical analysis we used the SAS software version 9.3 .

\section{Results}

\section{Baseline characteristics of patients}

One hundred fifty-eight patients were evaluated over a median follow-up time of 66 months (Inter quartile range [IQR] 24-101), whose characteristics are shown in Table 1. During the period of observation, KTD was observed in 42 (26.6\%) patients. No statistically significant differences were observed between patients with and without KTD regarding age, gender and ethnicity [non-Caucasian patients were 
Table 1 Characteristics of the study population

\begin{tabular}{|c|c|c|c|c|c|c|c|}
\hline \multirow[b]{2}{*}{ Female (\%) } & \multicolumn{2}{|c|}{$\begin{array}{l}\text { Overall population } \\
N=158\end{array}$} & \multicolumn{2}{|c|}{$\begin{array}{l}\text { Patients with KTD } \\
n=42\end{array}$} & \multicolumn{2}{|c|}{$\begin{array}{l}\text { Patients without KTD } \\
n=116\end{array}$} & \multirow{2}{*}{$\begin{array}{l}p^{*} \\
0.649\end{array}$} \\
\hline & 34 & $21.5 \%$ & 8 & $19.0 \%$ & 26 & $22.4 \%$ & \\
\hline Age [yrs] median (IQR) & 42 & $35-48$ & 42 & $37-45$ & 42 & $34-49$ & 0.591 \\
\hline Non-Caucasian (\%) & 5 & $3.2 \%$ & 2 & $4.8 \%$ & 3 & $2.6 \%$ & 0.490 \\
\hline $\mathrm{BMI}\left(\mathrm{Kg} / \mathrm{m}^{2}\right)$ median $(\mathrm{IQR})$ & 22,9 & $20,3-25,2$ & 23,5 & $20,7-25,4$ & 22,5 & $20,2-25,2$ & 0.339 \\
\hline TDF as part of first ARV regimen (\%) & 83 & $52,5 \%$ & 14 & $33,3 \%$ & 69 & $59,5 \%$ & 0.004 \\
\hline Previous therapy duration [yrs] median (IQR) & 0.0 & $0.0-6.1$ & 0.6 & $0.0-8.2$ & 0.0 & $0.0-3.8$ & 0.034 \\
\hline TDF duration (months) median (IQR) & 66 & 24-101 & 76 & $30-110$ & 59 & 23-95 & 0.090 \\
\hline Use of protease inhibitors (\%) & 103 & $65.2 \%$ & 26 & $61.9 \%$ & 77 & $66.4 \%$ & 0.602 \\
\hline CD4+ (cells/ $\mu \mathrm{L})$ median (IQR) & 373 & $228-599$ & 430 & $251-635$ & 371 & $224-580$ & 0.638 \\
\hline HIV-RNA (log cps/mL) median (IQR) & 3.8 & $0.0-5.0$ & 0.0 & $0.0-4.5$ & 4.0 & $0.0-5.0$ & 0.012 \\
\hline Creatinine (mg/dL) median (IQR) & 0.84 & $0.72-0.94$ & 0.84 & $0.70-0.99$ & 0.83 & $0.73-0.92$ & 0.534 \\
\hline GFR (MDRD equation) median (IQR) & 103 & $89-117$ & 106 & $89-118$ & 101 & $89-117$ & 0.586 \\
\hline HCV coinfection (\%) & 18 & $11.4 \%$ & 6 & $14.3 \%$ & 12 & $10.3 \%$ & 0.491 \\
\hline Diabetes (\%) & 11 & $7.0 \%$ & 5 & $11.9 \%$ & 6 & $5.2 \%$ & 0.142 \\
\hline Hypertension (\%) & 20 & $12.7 \%$ & 8 & $19.0 \%$ & 12 & $10.3 \%$ & 0.146 \\
\hline Bone disease $^{a}(\%)$ & 55 & $34.8 \%$ & 23 & $54.8 \%$ & 32 & $27.6 \%$ & 0.002 \\
\hline
\end{tabular}

Abbreviations: yrs. years, IQR Inter quartile range, cps copies, BMI body mass index, GFR glomerular filtration rate, MDRD The Modification of Diet in Renal Disease, $T D F$ tenofovir diproxil fumarate, ARV antiretroviral therapy; ${ }^{a}$ osteopenia/osteoporosis; ${ }^{*} p$ values are for $\mathrm{X} 2$ or Fisher's exact test and Mann-Whitney test

$2(4.8 \%)$ in the KTD group and $3(2.6 \%)$ in patients without KTD $p=0.490]$. Patients with KTD have a longer previous duration of therapy when compared with patients without KTD [0,6 years (IQR 0.0-8.29) vs 0,0 years (IQR 0.0-3.8); $p=0.034]$, accordingly KTD was present in a lower number of patients who received TDF as part of their initial antiretroviral regimen [14 (33,3\%) vs $69(59,5 \%) ; p=0,004]$. Furthermore, the duration of the TDF-containing regimen appeared to be longer in patients with KTD compared to that in patients without KTD although not statistically significant [76 months (IQR 30-110) vs 59 months (IQR 23-95); $p=0.090$ ]. In both groups, kidney function at baseline, evaluated through creatinine and GFR values, and body mass index were similar. About baseline comorbidities no differences were observed between the two groups regarding hypertension ad diabetes, while a higher prevalence of bone disease (osteopenia/osteoporosis) in patients with KTD [23 patients (54.8\%) vs 32 patients (27.6\%); $p=0.002]$ was observed.

\section{Genotype distribution and factors associated with KTD}

The distribution of the polymorphism for ABCC2, ABCC4 and $\mathrm{ABCC} 10$ are shown in Table 2. A significant statistical difference was observed in the distribution of the variant in rs1751034 of ABCC4 in patients with KTD when compared with patients without KTD. In particular the "GG" genotype at the position 3463 was more prevalent in patients with KTD [6 (14,3\%) vs 4 (3.5\%); $p=0.01$ ] (Fig. 1$)$. No statistical significant differences were observed among the ABCC2 rs 717,620 (-24 C > T) and ABCC10 rs2125739
( $\mathrm{T}>\mathrm{C}$ ) genotypes. As shown in Table 3, univariate analysis shows a significant association between KTD and the patients with the genotype GG at the position 3463 of ABCC4 [Odds ratio (OR) 4.667 (IC 95\% 1.247-17.464); $p=0.022$ ]. When we considered clinical parameters a significant association between bone diseases and KTD was observed [OR 3.178 (IC95\% 1.529-6.603); $p=0.002$ ], while an inverse correlation was observed between baseline HIV-RNA [OR 0.793 (IC 95\% 0.677-0.929); $p=0.004$ ] and receiving TDF as part of the initial antiretroviral regimen [OR 0,341 (IC 95\% 0.162-0.715); $p=0.004]$. In the multivariable model the association with the GG genotype was lost [OR 2.663 (IC95\% 0.610-11.621); $p=0.193$ ] whereas the association with bone disease maintained a statistical significance [OR 3.147 (IC95\% 1.361-7.279); $p=0.007$ ]. A trend between diabetes and KTD emerged [OR 3.670 (IC 95\% 0.91414.740); $p=0.067$ ] in parallel.

\section{Discussion}

We performed our study in a population setting of HIV-1 positive patients treated with TDF. The present study showed an increased prevalence of the variant rs1751034 of ABCC4 in HIV-1 positive patients treated with TDF manifesting signs of KTD; in particular an association with the risk of KTD and ABCC4 genotype "GG" was shown in bivariate analysis despite we could not confirm this finding in multivariable analysis. In vitro studies demonstrated the involvement of ABCC4 in the luminal efflux of adefovir and TDF in the kidney, thus justifying a decrease in the tubular drug secretion and an intracellular accumulation of 
Table 2 Distribution of different genotypes at ABCC2 rs 717,620 (-24 C > T), ABCC4 rs1751034 (3463 A > G) and ABCC10 rs2125739 $(T>C)$ in patients treated with tenofovir with or without KTD

\begin{tabular}{|c|c|c|c|c|c|c|c|}
\hline & \multicolumn{2}{|c|}{$\begin{array}{l}\text { Overall population } \\
N=158\end{array}$} & \multicolumn{2}{|c|}{$\begin{array}{l}\text { Patients with KTD } \\
n=42\end{array}$} & \multicolumn{2}{|c|}{$\begin{array}{l}\text { Patients without KTD } \\
n=116\end{array}$} & $p^{*}$ \\
\hline \multicolumn{8}{|c|}{ ABCC2 -24 C > T, rs717620 (\%) } \\
\hline $\mathrm{C} / \mathrm{C}$ & 104 & $65.8 \%$ & 25 & $59.5 \%$ & 79 & $68.1 \%$ & 0.503 \\
\hline$C / T$ & 52 & $32.9 \%$ & 16 & $38.1 \%$ & 36 & $31.0 \%$ & \\
\hline$T / T$ & 2 & $1.3 \%$ & 1 & $2.4 \%$ & 1 & $0.9 \%$ & \\
\hline \multicolumn{8}{|c|}{ ABCC4 3463 A > G, rs1751034 (\%) } \\
\hline $\mathrm{A} / \mathrm{A}$ & 92 & $58.2 \%$ & 27 & $64.3 \%$ & 65 & $56.0 \%$ & 0.010 \\
\hline$A / G$ & 56 & $35.5 \%$ & 9 & $21.4 \%$ & 47 & $40.5 \%$ & \\
\hline $\mathrm{G} / \mathrm{G}$ & 10 & $6.3 \%$ & 6 & $14.3 \%$ & 4 & $3.5 \%$ & \\
\hline \multicolumn{8}{|c|}{ ABCC10 rs2125739, T > C (\%) } \\
\hline$T / T$ & 80 & $50.6 \%$ & 19 & $45.2 \%$ & 61 & $52.6 \%$ & 0.394 \\
\hline $\mathrm{T} / \mathrm{C}$ & 66 & $41.8 \%$ & 21 & $50.0 \%$ & 45 & $38.8 \%$ & \\
\hline$C / C$ & 12 & $7.6 \%$ & 2 & $4.8 \%$ & 10 & $8.6 \%$ & \\
\hline
\end{tabular}

Abbreviations: KTD kidney tubular dysfunction, ABCC ATP-binding cassette; * $\mathrm{X} 2$

these drugs [14-16]. The association with polymorphisms of ABCC4, in particular 4976, and the presence of beta2 microglobulinuria in Thai HIV-1 positive patients was previously described by Likanonsakul et al. In the same population approximately $20 \%$ of patients manifested signs of KTD with a median of 5.04 years on TDF (IQR 3.9-6.7) [7]. This findings are similar with the prevalence of KTD observed in our cohort which has also a comparable previous period on TDF [5.5 years (IQR 2.0-8.5)]. In another study the same polymorphism was associated with a reduced exclusion of TDF, despite the plasmatic concentration of the drugs didn't differed between different genotypes at ABCC4 4976 [17]. In a previous study by RodríguezNóvoa et al. an association with the ABCC 4669 genotype $\mathrm{CC}$ and phosphorus wasting was observed [6]. This observation could partially explain our findings due to the fact

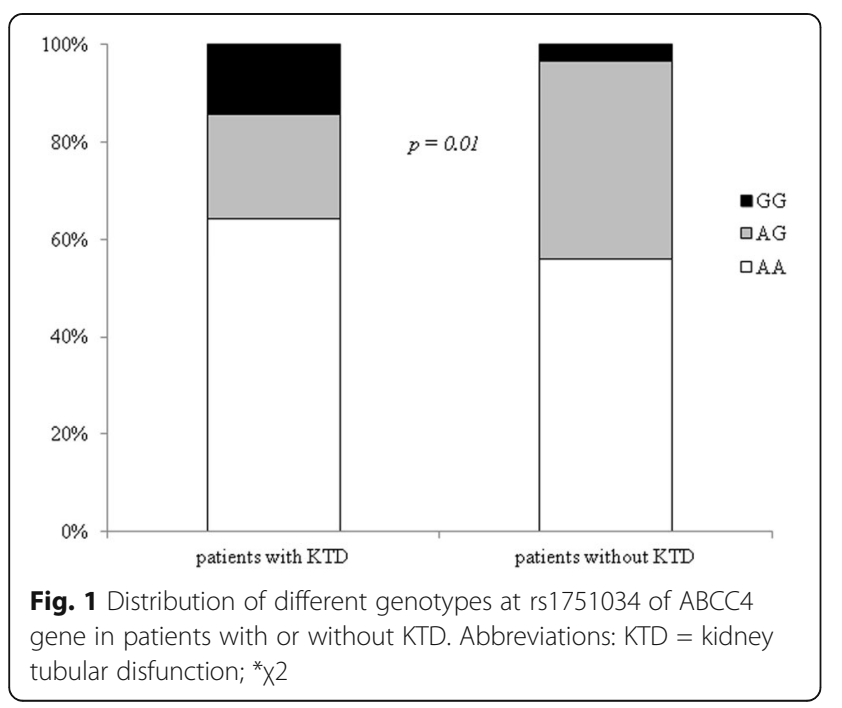

that we used phosphate wasting as a criteria to discriminate between patients with and without KTD. In a study in Japanese HIV positive patients no associations was observed between polymorphisms of ABCC4 and the risk of KTD, in the same study a strong association between the genotype $\mathrm{CC}$ at position -24 of $\mathrm{ABCC} 2$ gene was observed. We couldn't confirm these findings in our real life patients setting [9]. In another large study performed by Nishijima et al. in the same setting no association was observed between $\mathrm{ABCC} 2(-24 \mathrm{C}>\mathrm{T})$ and major renal outcome $(>10 \mathrm{ml} / \mathrm{min} / 1.73 \mathrm{~m} 2$ decrement in eGFR relative to baseline, $>25 \%$ decrement in eGFR, and eGFR $<60 \mathrm{ml} / \mathrm{min} /$ $1.73 \mathrm{~m} 2)$ related to TDF toxicities and the authors concluded that such SNPs are not to be considered a risk factor for clinical TDF-related renal dysfunction [18]. Similar findings were also reported in another study in which $\mathrm{ABCC} 2$ haplotypes was associated with renal proximal tubulopathy induced by TDF in HIV-1-infected patients, but no association was observed between ABCC4 polymorphism [19]. Despite several report of association of polymorphisms of ABCC2 and the development of KTD in patients treated with TDF it is notable that the exact mechanism by which these SNPs poses at risk of KTD development remains unknown. In particular MPR2 encoded by ABCC2 doesn't seems to be involved in the luminal transport of TDF in the tubular cells of the kidney [14]. In an in vitro study TDF renal tubular transport seems to be influenced by genetic variation of $\mathrm{ABCC} 10$, the authors suggested a possible implication in $\mathrm{ABCC} 10$ variations and the development of $\mathrm{ABCC} 10$ [10]. We weren't able to confirm the association of ABCC10 rs2125739 and KTD in our cohort. In our study, traditional risk factor for KTD like diabetes or hypertension are equally distributed between the patients with and without KTD with a general prevalence of $7 \%$ of 
Table 3 Logistic regression of factors involved in the development of KTD

\begin{tabular}{|c|c|c|c|c|c|c|c|c|}
\hline \multirow[b]{3}{*}{ Female vs male } & \multicolumn{4}{|c|}{ Bivariate analysis } & \multicolumn{4}{|c|}{ Multivariate analysis } \\
\hline & \multirow{2}{*}{$\begin{array}{l}\text { OR } \\
0,814\end{array}$} & \multicolumn{2}{|c|}{$(95 \% \mathrm{Cl})$} & \multirow{2}{*}{$\frac{p}{0,650}$} & \multirow[t]{2}{*}{ OR } & \multicolumn{2}{|c|}{$(95 \% \mathrm{Cl})$} & \multirow[t]{2}{*}{$p$} \\
\hline & & 0,336 & 1974 & & & & & \\
\hline Caucasian vs Non-Caucasian & 1883 & 0,304 & 11,684 & 0,497 & & & & \\
\hline Baseline age (per yrs) & 0,989 & 0,956 & 1023 & 0,524 & & & & \\
\hline $\mathrm{BMI} \leq 18$ vs $>18$ & 1133 & 0,335 & 3840 & 0,841 & & & & \\
\hline TDF as part of first ARV regimen vs TDF as part of second or further ARV regimens & 0,341 & 0,162 & 0,715 & 0,004 & 1040 & 0,195 & 5537 & 0,963 \\
\hline Previous therapy duration (per yrs) & 1057 & 0,988 & 1131 & 0,110 & 0,948 & 0,854 & 1051 & 0,309 \\
\hline Baseline CD4 cell count (per cells/mL) & 1000 & 0,999 & 1001 & 0,907 & & & & \\
\hline Baseline Plasma HIV-RNA level (per log cps/mL) & 0,793 & 0,677 & 0,929 & 0,004 & 0,809 & 0,578 & 1132 & 0,216 \\
\hline HCV coinfection & 1444 & 0,505 & 4131 & 0,493 & & & & \\
\hline Baseline creatinine (per mg/dL) & 1999 & 0,138 & 28,861 & 0,611 & & & & \\
\hline Duration of treatment with TDF (per months) & 1006 & 0,998 & 1015 & 0,162 & 0,998 & 0,987 & 1009 & 0,672 \\
\hline Use of protease inhibitors & 0,823 & 0,396 & 1712 & 0,602 & & & & \\
\hline Hypertension & 2039 & 0,769 & 5405 & 0,152 & 0,991 & 0,318 & 3084 & 0,987 \\
\hline Diabetes & 2477 & 0,714 & 8595 & 0,153 & 3670 & 0,914 & 14,740 & 0,067 \\
\hline Bone disease $\mathrm{a}^{\mathrm{a}}$ & 3178 & 1529 & 6603 & 0,002 & 3147 & 1361 & 7279 & 0,007 \\
\hline ABCC2-24 C > T (CC vs CT/TT) & 0,689 & 0,332 & 1428 & 0,316 & & & & \\
\hline ABCC4 3463 A > G (GG vs AG/AA) & 4667 & 1247 & 17,464 & 0,022 & 2663 & 0,610 & 11,621 & 0,193 \\
\hline ABCC10 rs2125739 T > C (CC vs TC/TT) & 0,530 & 0,111 & 2525 & 0,425 & & & & \\
\hline
\end{tabular}

Abbreviations: $O R$ odds ratio, $C l$ confidence interval, cps copies, yrs. years, $B M I$ body mass index, KTD kidney tubular dysfunction, $A B C C$ ATP-binding cassette, ARV antiretroviral therapy; ${ }^{a}$ osteopenia/osteoporosis; TDF tenofovir diproxil fumarate; $p$ values are for $\mathrm{X}^{2}$

diabetes and $12 \%$ of hypertension. In multivariable analysis a trend was observed with diabetes posing patients at greater risk of developing KTD. It's important to manage this modifiable classic risk factors for kidney damage especially when no clear-cut results are available from basic research and a lacking association remain with SNPs and KTD [20]. We observed a significantly higher prevalence of bone disease in patients with signs of KTD when compared with patients without $\mathrm{KTD}(54,8$ vs $27,6 \% ; p=0.002)$ and a strong association between bone disease an KTD was also confirmed in the multivariable analysis. As previously described in HIV positive patients treated with TDF a strong association was observed between KTD and a lower bone mineral density [21, 22]. In addition the prevalence of bone disease (osteopenia/osteoporosis) such as the prevalence of KTD was similar to previous report by Calmy et al. [23].

Our study has several limitations, in particular the retrospective design of the study exposed the analysis to biases due to the lack of data that hadn't been reported. The single centre design reduce the applicability of our findings to other cohorts, e.g. we have a very little presence in this study of non-Caucasian patients. Due to the limited size of our sample, we cannot rule out that the association of the genotype GG at ABCC4 3463 with tubulopathy could be driven by chance. The high prevalence of bone disease in our population could suggest also a channelling bias due to the selection of patients picked out in clinical practice - roughly one third of patients who had been taking TDF - for genotypization due to the concomitant presence of comorbidities. The criteria used to define KTD were also subjected to limitation due to the potential intervention of confounders and lack of specificity for proximal tubular damage.

\section{Conclusions}

We observed an association between the variant rs 1,751,034 of ABCC4 and KTD in our single centre cohort of HIV patients treated with TDF. A strong association between bone disease and KTD was also observed. This finding should prompt our attention on the parallel onset of these 2 co-morbidities and the consequent effort to manage affected subjects in a timely manner.

\section{Abbreviations}

ABC: ATP-binding cassette; HIV-1: Human immunodeficiency virus type 1; IQR: Inter quartile range; KTD: Kidney tubular dysfunction; MRP: MultidrugResistance Proteins; SD: Standard deviation; SNPs: Single-Nucleotide Polymorphism; TDF: Tenofovir disoproxil fumarate

\section{Acknowledgements}

We thanks Mrs. Tiziana Formenti for the excellent technical help.

Funding

No financial support to this study.

\section{Availability of data and materials}

The data sets used and/or analyzed during the current study available from the corresponding author on reasonable request. 


\section{Authors' contributions}

SES, AG, FSF, MG, SR designed the study. SR, PM, CA included the patients. $\mathrm{SES}, \mathrm{AG}, \mathrm{FSF}, \mathrm{SR}, \mathrm{PM}, \mathrm{CA}$ were involved in data collection and interpretation. FSF, EGIC performed laboratory analyses. AG, MLO were responsible for the statistical analyses. All authors interpreted the data and drafted the manuscript. All authors have critically revised and approved the final version.

\section{Competing interests}

S.R. received grants, fees for speaker's bureau, advisory boards and CME activities from BMS, ViiV, MSD, AbbVie, Gilead, Janssen and Pfizer. M.G. received grants, fees for speaker's bureau, advisory boards and CME activities from BMS, ViiV, MSD, AbbVie, Gilead, Janssen and Roche. This manuscript was partially presented at the HIV Therapy Conference, Glasgow, 23-26 October 2016, P317.

\section{Consent for publication}

Not applicable

\section{Ethics approval and consent to participate}

This retrospective research was conducted on data collected for clinical purposes. All data used in the study were previously anonymized, according to the requirements set by Italian Data Protection Code (leg. Decree 196/2003) and by the General authorizations issued by the Data Protection Authority. Approval by Ethics Committee was deemed unnecessary because, under Italian law, such an approval is required only in the hypothesis of prospective clinical trials on medical products for clinical use (art. 6 and art. 9, leg. Decree 211/ 2003). Written informed consent for medical procedures/interventions performed for routine treatment purposes was collected for each patient.

\section{Declarations}

We did not receive any financial help for the preparation of the manuscript.

\section{Publisher's Note}

Springer Nature remains neutral with regard to jurisdictional claims in published maps and institutional affiliations.

\section{Author details}

'Infectious Diseases Unit, DIBIC Luigi Sacco - University of Milan, Milan, Italy. ${ }^{2}$ ASST Fatebenefratelli-Sacco, Clinical Pharmacology Department, Milan, Italy. ${ }^{3}$ ASST Fatebenefratelli-Sacco, First Division of Infectious Diseases, Milan, Italy. ${ }^{4}$ Clinical Pharmacology Unit, Consiglio Nazionale delle Ricerche Institute of Neuroscience, DIBIC Luigi Sacco - University of Milan, Milan, Italy. ${ }^{5}$ E. Medea Scientific Institute, Bosisio Parini, Italy.

Received: 13 April 2017 Accepted: 28 May 2017

Published online: 05 June 2017

\section{References}

1. Hemkens LG, Ewald H, Santini-Oliveira M, et al. Comparative effectiveness of tenofovir in treatment-naïve HIV-infected patients: systematic review and meta-analysis. HIV Clin Trials. 2015 Oct;16(5):178-89.

2. Hamzah $L$, Booth JW, Jose $S$, et al. HIVCKD study. Renal tubular disease in the era of combination antiretroviral therapy. Aids. 2015 Sep 10;29(14):1831-6.

3. Hall AM, Hendry BM, Nitsch D, Connolly JO. Tenofovir-associated kidney toxicity in HIV-infected patients: a review of the evidence. Am J Kidney dis. 2011 May; $57(5): 773-80$

4. Maggi $P$, Bartolozzi $D$, Bonfanti $P$, et al. Renal complications in HIV disease: between present and future. AIDS rev. 2012 Jan-Mar;14(1):37-53.

5. Rungtivasuwan K, Avihingsanon A, Thammajaruk N, et al. Influence of ABCC2 and $A B C C 4$ polymorphisms on tenofovir plasma concentrations in Thai HIV-infected patients. Antimicrob Agents Chemother. 2015:59(6):3240-5.

6. Rodríguez-Nóvoa S, Labarga P, Soriano V, et al. Predictors of kidney tubular dysfunction in HIV-infected patients treated with tenofovir: a pharmacogenetic study. Clin Infect dis. 2009 Jun 1;48(11):e108-16.

7. Likanonsakul S, Suntisuklappon B, Nitiyanontakij R, et al. A single-nucleotide polymorphism in ABCC4 is associated with Tenofovir-related Beta2Microglobulinuria in Thai patients with HIV-1 infection. PLoS One. 2016 Jan 25:11(1):e0147724.

8. Achhra AC, Nugent M, Mocroft A, Ryom L, Wyatt CM. Chronic kidney disease and antiretroviral therapy in HIV-positive individuals: recent developments. Curr HIV/AIDS rep. 2016 Jun;13(3):149-57.
9. Nishijima $T$, Komatsu $H$, Higasa $K$, et al. Single nucleotide polymorphisms in ABCC2 associate with tenofovir-induced kidney tubular dysfunction in Japanese patients with HIV-1 infection: a pharmacogenetic study. Clin Infect dis. 2012 Dec;55(11):1558-67.

10. Pushpakom SP, Liptrott NJ, Rodríguez-Nóvoa S, et al. Genetic variants of ABCC10, a novel tenofovir transporter, are associated with kidney tubular dysfunction. J Infect dis. 2011 Jul 1;204(1):145-53.

11. Manosuthi W, Sukasem C, Thongyen S, Nilkamhang S, Sungkanuparph S. $A B C C 2^{*} 1 C$ and plasma tenofovir concentration are correlated to decreased glomerular filtration rate in patients receiving a tenofovir-containing antiretroviral regimen. J Antimicrob Chemother. 2014 Aug:69(8):2195-201.

12. Estrella MM, Fine DM. Screening for chronic kidney disease in HIV-infected patients. Adv Chronic Kidney dis. 2010 Jan;17(1):26-35.

13. Casado JL, Bañón S, Santiuste C, et al. Prevalence and significance of proximal renal tubular abnormalities in HIV-infected patients receiving tenofovir. Aids. 2016 Jan;30(2):231-9.

14. Ray $\mathrm{AS}$, Cihlar $\mathrm{T}$, Robinson $\mathrm{KL}$, et al. Mechanism of active renal tubular efflux of tenofovir. Antimicrob Agents Chemother. 2006 Oct;50(10):3297-304.

15. Imaoka T, Kusuhara H, Adachi M, Schuetz JD, Takeuchi K, Sugiyama Y. Functional involvement of multidrug resistance-associated protein 4 (MRP4/ $A B C(4)$ in the renal elimination of the antiviral drugs adefovir and tenofovir. Mol Pharmacol. 2007 Feb;71(2):619-27.

16. Kohler JJ, Hosseini $\mathrm{SH}$, Green E, et al. Tenofovir renal proximal tubular toxicity is regulated by OAT1 and MRP4 transporters. Lab Investig. 2011 Jun;91(6):852-8.

17. Calcagno A, Cusato J, Marinaro L, et al. Clinical pharmacology of tenofovir clearance: a pharmacokinetic/pharmacogenetic study on plasma and urines. Pharmacogenomics J. 2015 Oct 6; doi:10.1038/tpj.2015.71

18. Nishijima T, Hayashida T, Kurosawa T, Tanaka N, Oka S, Gatanaga H. Drug transporter genetic variants are not associated with TDF-related renal dysfunction in patients with HIV-1 infection: a Pharmacogenetic study. PLoS One. 2015 Nov 4;10(11):e0141931.

19. Izzedine H, Hulot JS, Villard E, et al. Association between ABCC2 gene haplotypes and tenofovir-induced proximal tubulopathy. J Infect dis. 2006 Dec 1;194(11):1481-91. Epub 2006 Oct 26

20. Lucas GM, Ross MJ, Stock PG, et al. HIV medicine Association of the Infectious Diseases Society of America. Clinical practice guideline for the management of chronic kidney disease in patients infected with HIV: 2014 update by the HIV medicine Association of the Infectious Diseases Society of America. Clin Infect dis. 2014 Nov 1;59(9):e96-138.

21. Hamzah $L$, Samarawickrama A, Campbell $L$, et al. Effects of renal tubular dysfunction on bone in tenofovir-exposed HIV-positive patients. Aids. 2015 Sep 10;29(14):1785-92.

22. Casado JL, Santiuste C, Vazquez M, et al. Bone mineral density decline according torenal tubular dysfunction and phosphaturia in tenofovirexposed HIV-infectedpatients. Aids. 2016 Jun 1;30(9):1423-31.

23. Calmy A, Fux CA, Norris R, et al. Low bone mineral density, renal dysfunction, and fracture risk in HIV infection: a cross-sectional study. J Infect dis. 2009 Dec 1;200(11):1746-54

\section{Submit your next manuscript to BioMed Central} and we will help you at every step:

- We accept pre-submission inquiries

- Our selector tool helps you to find the most relevant journal

- We provide round the clock customer support

- Convenient online submission

- Thorough peer review

- Inclusion in PubMed and all major indexing services

- Maximum visibility for your research

Submit your manuscript at www biomedcentral.com/submit
BioMed Central 